\title{
Performance of point-of-care international normalized ratio measurement to diagnose trauma-induced coagulopathy
}

Thomas Mistral 1,2,3, Yvonnick Boué1, Jean-Luc Bosson ${ }^{2,4}$, Pauline Manhes', Jules Greze ${ }^{1,2,3}$, Julien Brun', Pierre Albaladejo ${ }^{1,2}$, Jean-François Payen ${ }^{1,2,3}$ and Pierre Bouzat ${ }^{1,2,3^{*}}$

\begin{abstract}
Background: Trauma-induced coagulopathy (TIC) is a common feature after severe trauma. Detection of TIC is based upon classic coagulation tests including international normalized ratio (INR) value. Point-of-care (POC) devices have been developed to rapidly measure INR at the bedside on whole blood. The aim of the study was to test the precision of the Coagucheck ${ }^{\circledast}$ XS Pro device for INR measurement at hospital admission after severe trauma.

Methods: We conducted a prospective observational study in a French level I trauma center. From January 2015 to May 2016, 98 patients with a suspicion of a post-traumatic acute hemorrhage had POC-INR measurement on whole blood concomitantly to classic laboratory INR determination (lab-INR) on plasma at hospital admission. The agreement between the two methods in sorting three predefined categories of INR (normal coagulation, moderate TIC and severe TIC) was evaluated using the Cohen's kappa test with a quadratic weighting. The correlation between POC-INR and lab-INR was measured using the Pearson's coefficient. We also performed a Bland and Altman analysis.

Results: The agreement between the lab-INR and the POC-INR was moderate (Kappa $=0.45[95 \% \mathrm{Cl} 0.36-0.50])$ and the correlation between the two measurements was also weak (Pearson's coefficient $=0.44$ [95\% Cl 0.27-0.59]). Using a Bland and Altman analysis, the mean difference (bias) for INR was 0.22 [95\% Cl 0.02-0.42], and the standard deviation (precision) of the difference was 1.01.

Discussion/conclusion: POC Coagucheck ${ }^{\oplus}$ XS Pro device is not reliable to measure bedside INR. Its moderate agreement with lab-INR weakens the usefulness of such device after severe trauma.
\end{abstract}

Trial registration: NCT02869737. Registered 9 August 2016.

\section{Background}

Trauma-induced coagulopathy (TIC) is a common phenomenon after severe trauma and is associated with transfusion requirements, risk of complications and mortality [1]. Early detection of TIC is based upon early and repeated monitoring of coagulation using a traditional laboratory determination of prothrombin time (PT), international normalized ratio (INR), activated partial thromboplastin time (APTT) platelet counts and fibrinogen [2]. Specifically, elevated INR was associated

\footnotetext{
* Correspondence: PBouzat@chu-grenoble.fr

'Grenoble Alpes Trauma Center, Pôle Anesthésie-Réanimation, CHU Grenoble Alpes, F-38000 Grenoble, France

${ }^{2}$ University Grenoble Alpes, F-38000 Grenoble, France

Full list of author information is available at the end of the article
}

with death, multiple organ failure, and longer stay in hospital after severe trauma [3, 4]. This parameter also predicted accurately the requirement for red blood cell transfusion, including massive transfusion, in the context of trauma [5]. However, classic coagulation tests depend on laboratory processing, which are often delayed from the blood puncture. To overcome these limitations, point-of-care (POC) devices have been implemented to obtain a bedside assessment of the coagulation status on whole blood using viscoelastic method or bedside measurement of INR. Hence, POC-INR measurement device may provide a rapid, repeatable and low-cost measurement of real-time INR. Few studies evaluated POC devices for the diagnosis of TIC in the trauma bay [6-9]. In these 
studies, POC-INRs were obtained with significant gain in time compared with laboratory INRs (lab-INR), but their agreement with lab-INRs and their precision to diagnose TIC differed significantly. None of these studies used the Coagucheck $^{\ominus}$ XS Pro device after severe trauma.

The aim of our study was to evaluate the precision of INR measurement with POC Coaguchek ${ }^{\circ}$ XS Pro device at the admission of severe trauma patients. We hypothesized an almost perfect agreement between POC-INR measurement and lab-INR measurement.

\section{Methods}

\section{Study design and patients}

We conducted a prospective observational study in a level-I trauma center (Grenoble University Hospital, France) from January 2015 to May 2016. The Regional Institutional Ethics Committee (CECIC Rhône-AlpesAuvergne, Clermont-Ferrand, IRB file number 2015-03, approval on January 13, 2015) approved the study design and, given its observational nature, waived the requirement for written informed consent. The study is recorded in clinicaltrials.gov, number: NCT02869737.

Inclusion criteria were patients older than 15 years-old admitted into the trauma bay for a suspicion of posttraumatic acute hemorrhage. Consecutive severe trauma patients were eligible if they had on admission at least one of the following items: 1) an hemodynamic instability defined by a systolic arterial blood pressure (SBP) $\leq$ $90 \mathrm{mmHg}, 2)$ an hemodynamic stability (SBP $>90 \mathrm{mmHg}$ ) with the use of vasopressor or fluid therapy $>20 \mathrm{~mL} / \mathrm{kg}$, 3) a red blood cell transfusion before hospital admission, or 4) a specific post-traumatic lesion at high risk of coagulopathy: traumatic brain injury with a Glasgow Coma Score $<13$ before any sedation, severe chest trauma with first recorded pre-hospital pulse oximetry $\leq 92 \%$, abdominal injury with positive ultrasonography, penetrating trauma, suspicion of spine injury, suspicion of pelvic ring fracture, or proximal amputation. Non-inclusion criteria were pregnant women, or a medical history interfering with the coagulation process (severe hepatic failure, cholestasis, digestive malabsorption, oral anticoagulation, heparin-based anticoagulation treatment, or fat-soluble vitamin deficiency).

\section{Study protocol and data collection}

Patients were prospectively included at hospital admission. The following clinical data were collected: age, sex, vital variables on admission (GCS, SBP, Heart rate, and $\mathrm{SpO}_{2}$ ), transfusion requirements, Injury Severity Score (ISS), Sequential organ failure assessment (SOFA) on day 1, length of stay in intensive care unit (ICU), and in-hospital mortality. Regarding biological data, blood samples were drawn for central laboratory analysis. Coagulation assays with citrated-tube were collected to measure prothrombin time (PT) for the calculation of lab-INR $[\mathrm{INR}=(\mathrm{PT}$ patient / PT normal) ${ }^{\text {ISI}}$, ISI: International sensitivity index], APTT, and fibrinogen concentration. The Lab-INR was performed on a STA-R evolution coagulometer (Stago, Asnières, France) using STA ${ }^{\circ}$-Neoplastine ${ }^{\circ} \mathrm{CI}$ Plus (Stago) reagent. The coefficient of variation for the lab-INR was between 2.9 and $4.9 \%$. The average time from the blood puncture to the lab-INR measurement was approximately $30 \mathrm{~min}$ in our center. Concomitantly, an independent nurse measured POC INR from the same blood puncture (POC-INR) with the Coaguchek ${ }^{\circ}$ XS Pro (Roche laboratory, Meylan, France) device. POC-INR values were recorded in a case report form (CRF), and were not transmitted to the physician in charge of the patient.

\section{POC measurements}

All measurements were obtained with a unique device to maximize reproducibility. The POC Coaguchek $^{\circ} \mathrm{XS}$ Pro consists of an amperometric determination of the PT after activation of the coagulation with human recombinant thromboplastin. Conditions of testing respected carefully constructor's recommendations. At the patient's bedside, whole blood from venous puncture was used to release a drop (at least $8 \mu \mathrm{l}$ ) on a specific strip, which was inserted into the hand-sized device to provide POC-INR. ISI of Coaguchek $\mathrm{k}^{\circ}$ XS Pro was 1.0. The procedure was easy-going for any qualified nurse, and very fast (approximately $1 \mathrm{~min}$ ). Two types of quality control were performed: each strip was tested before use to detect deteriorated strips and the POC device was itself monitored monthly with a specific control-kit as recommended by the constructor. These tests were mandatory to perform POC-INR measurements and could not be overdriven. The coefficient of variation for the POC-INR was measured between 3.4 and $6 \%$ by the company.

\section{Endpoints}

Primary outcome was the concordance in categorical sorting between POC-INR and lab-INR on admission. INR values were sorted in three categories: 1 ) normal INR value: INR $<1.2$; 2) moderate TIC: $1.2 \leq$ INR $<1.5$; 3 ) severe TIC: INR $\geq 1.5$ according to Frith et al. [3] and Peltan at al. [4].

Secondary outcomes were 1) the correlation between POC-INR and lab-INR values, and 2) the characteristics of the trauma population according to their lab-INR category.

\section{Study size}

To be clinically relevant, we expected a kappa coefficient equal to 0.95 between POC-INR and lab-INR. The number of patients to include was set at 100 to obtain a $95 \%$ confidence interval $(95 \% \mathrm{CI})$ between 0.85 and 0.99 . 


\section{Statistical analysis}

Descriptive statistics included frequencies for categorical variables, and median values (25th-75th percentiles) for continuous variables. The concordance between POCINR and lab-INR in sorting the three pre-defined classes of INR was analyzed using Cohen's Kappa test with a quadratic weighting. Using the laboratory measurement as the gold standard, we performed a linear regression analysis to test the correlation between labINR and POC-INR and calculated the Pearson correlation coefficient. Statistical analysis was performed with the software STATA 13.1 (Stata Corp ${ }^{\circ}$, College Station, TX). Pearson's coefficients and Kappa test were presented with their 95\% confidence interval (95\% CI). Agreement between the two methods was also assessed by the method of Bland and Altman, calculating the mean difference (bias, d) with the standard deviation of the differences (precision, $\mathrm{s}$ ) and the limits of agreement $(\mathrm{d} \pm 2 \mathrm{~s})$.

\section{Results}

Flow chart of eligible patients and reasons for noninclusion are presented in Fig. 1. Within the study period, 100 patients were included. As two patients with an age lower than 15-year-old were wrongly included, 98 severe trauma patients were considered for final analysis with no missing data on the primary outcome (complete case analysis). Patient's characteristics are presented in Table 1. Median lab-INR was 1.2 [1.1-1.3], with 46 patients with normal coagulation state, 35 patients with moderate TIC, and 17 patients with severe TIC. Characteristics of the study population according to their labINR category are presented in Table 1 . The agreement between the POC-INR the lab-INR in sorting the three predefined classes of INR was moderate with a kappa equal to 0.45 [95\% CI 0.36-0.50] (Table 2). The correlation between POC-INR values and lab-INR values was weak with a Pearson's coefficient equal to 0.44 [95\% CI 0.27-0.59] (Fig. 2). Using Bland-Altman analysis, the overall mean difference (bias, d) was 0.22 [95\% CI 0.02-0.42], and standard deviation of the differences (precision, $\mathrm{s}$ ) was 1.01. Figure 3 presents the limits of agreement $(d \pm 1.96 \mathrm{~s}$, from -1.76 to 2.20 ).

\section{Discussion}

Early diagnosis of TIC at hospital admission is part of the global medical strategy for the management of severe trauma patients. Using a POC-INR measurement device at the bedside, we found a moderate agreement between this POC method and the classic laboratory

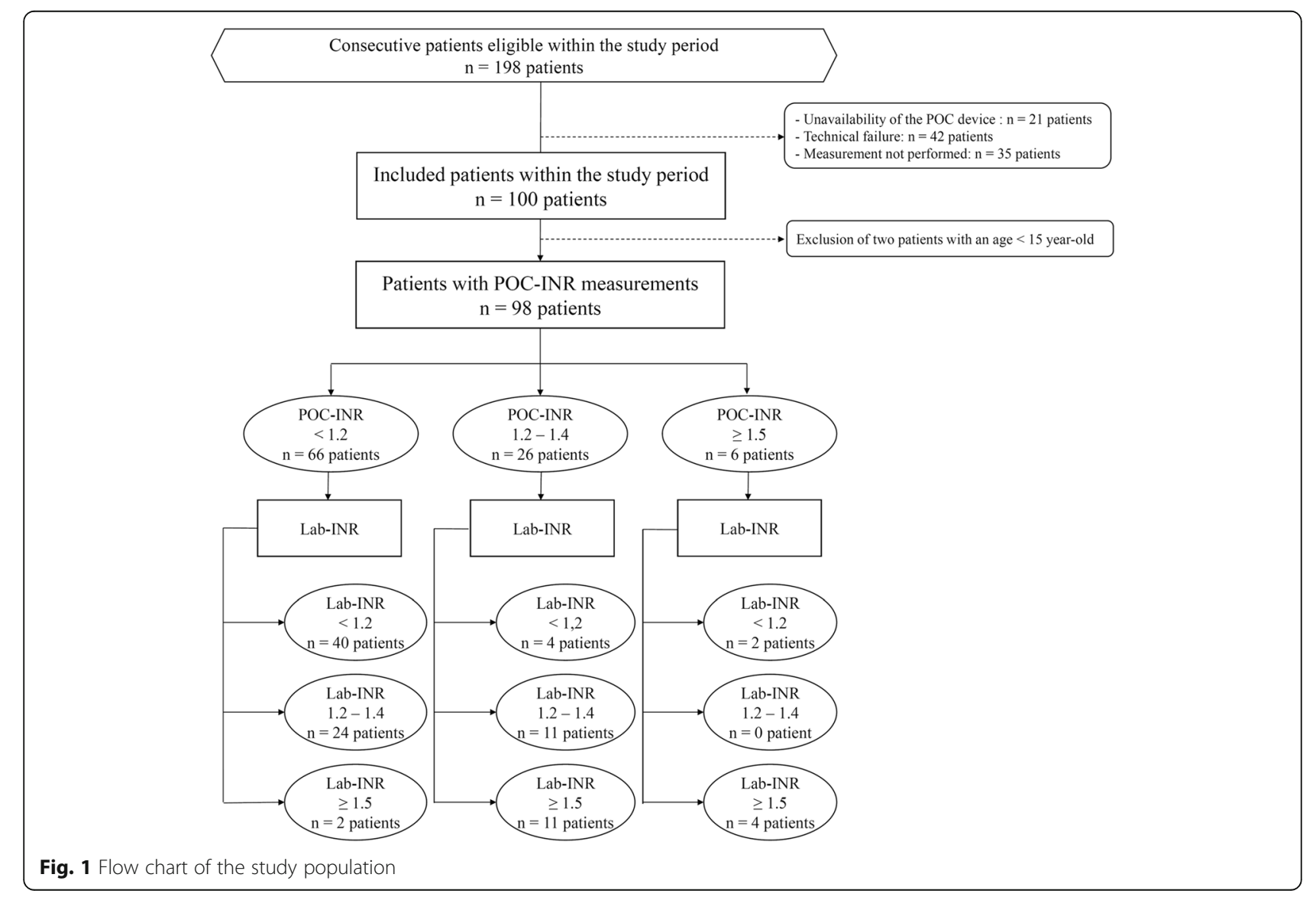


Table 1 Characteristics of the whole study population and according to their coagulation status on admission. Normal coagulation status was defined by a laboratory INR (lab-INR) $<1.2$, moderate trauma-induced coagulopathy (TIC) by $1.2 \leq$ lab-INR $<1.5$, and severe TIC by a lab-INR $\geq 1.5$

\begin{tabular}{|c|c|c|c|c|}
\hline Variables & $\begin{array}{l}\text { Lab-INR }<1.2 \\
n=46 \text { patients }\end{array}$ & $\begin{array}{l}\text { Lab-INR [1.2-1.5] } \\
n=35 \text { patients }\end{array}$ & $\begin{array}{l}\text { Lab-INR } \geq 1.5 \\
n=17 \text { patients }\end{array}$ & $\begin{array}{l}\text { Total population } \\
N=98 \text { patients }\end{array}$ \\
\hline Age, years & $42[30-55]$ & $41[22-55]$ & $44[35-48]$ & $42[27-55]$ \\
\hline Male, n (\%) & $41(89)$ & $34(97)$ & $17(100)$ & 92 \\
\hline Blunt trauma, n (\%) & $40(87)$ & $33(94)$ & $13(76)$ & 86 \\
\hline Patients with pre-hospital fluid therapy $>20 \mathrm{ml} / \mathrm{kg}, \mathrm{n}(\%)$ & $24(52)$ & $18(51)$ & $11(65)$ & 53 \\
\hline Patients with pre-hospital RBC transfusion, n (\%) & $1(2)$ & $2(6)$ & $3(18)$ & 6 \\
\hline Patients with pre-hospital mechanical ventilation, n (\%) & $10(22)$ & $17(49)$ & $11(65)$ & 38 \\
\hline First recorded pre-hospital pulse oximetry (SpO2), \% & 96 [92-98] & 94 [87-97] & $48[0-96]$ & 96 [89-98] \\
\hline Patients with first recorded SpO2 $\leq 92 \%, \mathrm{n}(\%)$ & $9(20)$ & $10(29)$ & $3(18)$ & 22 \\
\hline \multicolumn{5}{|l|}{ Vital variables on admission } \\
\hline Heart rate, Beats/min & $80[70-105]$ & $93[70-110]$ & $95[75-100]$ & 89 [10-105] \\
\hline Systolic arterial blood pressure, $\mathrm{mmHg}$ & 120 [110-140] & 120 [110-135] & $90[75-110]$ & 120 [103-140] \\
\hline $\mathrm{SBP} \leq 90 \mathrm{mmHg}, \mathrm{n}(\%)$ & $4(9)$ & $4(11)$ & $11(65)$ & 19 \\
\hline Glasgow Coma Scale before sedation & 15 [12-15] & $11[6-15]$ & $3[3-14]$ & $14[6-15]$ \\
\hline Patients with GCS < 13, n (\%) & $12(26)$ & $18(51)$ & $10(59)$ & 40 \\
\hline Patients treated with tranexamic acid, n (\%) & 12 & 8 & 12 & 32 \\
\hline Patients with vasopressor on admission, $\mathrm{n}(\%)$ & $20(43)$ & $18(51)$ & $16(94)$ & 54 \\
\hline Positive Focused Assessment Sonography for Trauma, n (\%) & $12(26)$ & $15(43)$ & $10(59)$ & 37 \\
\hline POC INR on admission & $1.0[1.0-1.1]$ & $1.1[1.1-1.2]$ & $1.3[1.2-1.4]$ & $1.1[1.0-1.2]$ \\
\hline \multicolumn{5}{|l|}{ Laboratory coagulation variables on admission } \\
\hline Prothrombin time (PT), \% & $92[87-100]$ & $72[70-77]$ & $45[40-53]$ & 79 [70-92] \\
\hline INR & $1.1[1.0-1.1]$ & $1.2[1.2-1.3]$ & $1.8[1.6-2.0]$ & $1.2[1.1-1.3]$ \\
\hline Activated partial thromboplastin time (APTT), sec & $28.8[27.2-31.4]$ & $30.8[29.8-33.7]$ & $50.5[37.1-57.5]$ & $30.8[28.6-35.4]$ \\
\hline Fibrinogen concentration, $\mathrm{g} / \mathrm{L}$ & $2.7[2.4-3.0]$ & $2.2[2.0-2.6]$ & $1.4[1.0-1.6]$ & $2.3[2-2.8]$ \\
\hline Serum lactate concentration on admission, $g / L$ & $1.7[1.0-2.7]$ & $2.0[1.3-3.7]$ & $5.7[3.5-9.1]$ & $2.2[1.4-4.3]$ \\
\hline Patients with RBC transfusion within 24 h, n (\%) & $3(7)$ & $5(14)$ & $12(71)$ & 20 \\
\hline Patients with FFP transfusion within 24 h, n (\%) & $1(2)$ & $3(9)$ & $11(65)$ & 15 \\
\hline Injury Severity Score (ISS) & 25 [14-29] & 25 [13-38] & $34[25-43]$ & $25[16-34]$ \\
\hline Sequential organ failure assessment (SOFA) at day 1 & $3[0-5]$ & $5[0-7]$ & $8[5-10]$ & $4[0-7]$ \\
\hline Length of stay in ICU. days & $5[2-10]$ & $8[3-14]$ & $1[1-10]$ & $5[1-12]$ \\
\hline In-hospital mortality. n (\%) & $3(7)$ & $5(14)$ & $8(47)$ & 16 \\
\hline
\end{tabular}

Data are median (25th-75th percentiles). FFP fresh frozen plasma, ICU intensive care unit, ISS Injury Severity Score, RBC red blood cell

determination of INR. The correlation between these two methods was not acceptable and the precision of POC-INR was poor. Taken together, these findings challenged the usefulness of this POC-INR measurement device to diagnose TIC at the bedside.

POC-INR devices were originally implemented to monitor patients with oral anticoagulation by vitamin- $\mathrm{K}$ antagonist [10-15]. Potential utilization have been extended to monitor coagulation state in the operating room [16], in the military setting [17], in emergency departments [18], and in the pre-hospital field [19]. From the severe trauma standpoint, the main interest of a bedside INR assessment lies in early diagnosis of trauma-induced coagulopathy. Bedside and real-time measurement of the INR would allow physicians to individualize hemostatic treatment while avoiding futile transfusion of coagulation factors. Despite encouraging preliminary reports, our study showed poor precision of POC-INR to estimate lab-INR. Indeed, its agreement and its correlation with lab-INR were not sufficient for clinical use. For instance, the limits of agreement between the two methods using Bland and Altman analysis were -1.96 (lower limit of agreement) and +2.20 (upper limit of agreement). Considering that INR is mostly measured 
Table 2 Concordance between the laboratory INR (lab-INR) and the point-of-care INR (POC-INR) in sorting three INR categories: normal INR (INR <1.2). moderate trauma-induced coagulopathy (TIC) $(1.2 \leq I N R<1.5)$. and severe $T I C(I N R \geq 1.5)$. Bolded values represent the number of patients accordingly classified by both methods

\begin{tabular}{lllll}
\hline & lab-INR $<1.2$ & $1.2 \leq$ lab-INR $<1.5$ & lab-INR $\geq 1.5$ & Total \\
\hline POC-INR $<1.2$ & $\mathbf{4 0}$ & 24 & 2 & 66 \\
$1.2 \leq$ POC-INR $<1.5$ & 4 & $\mathbf{1 1}$ & 11 & 26 \\
POC-INR $\geq 1.5$ & 2 & 0 & $\mathbf{4}$ & 6 \\
Total & 46 & 35 & 17 & 98 \\
\hline
\end{tabular}

Values are numbers. INR international normalized ratio, lab laboratory, POC point-of-care

Bold values are correct concordance between the two methods

between 1 and 3, such differences are relevant from the clinical standpoint. Specifically, the Fig. 2 revealed possible high discrepancy between the POC method and the lab method in two patients (lab-INR equal to 6 and 10, whereas POC-INR was lower than 2). These discrepancies were repeatedly controlled in these two patients and were not related to either lab-INR errors or blood contamination. Our results are inconsistent with a previously reported correlation between lab-INR and POC-INR using the INRatio Monitoring-System (Hemosense, Milpitas, CA) in severe trauma patients but are consistent with results obtained with the Hemochron Signature Elite device (International Techidyne Corporation, Edison, NJ) in the context of acute hemorrhage and with another POC-INR device after severe trauma [8]. To our knowledge, our study is the largest prospective cohort of severe trauma patients that evaluates a POC-INR device at hospital admission. Methodological factors could explain the disagreement between POC-INR measurements and laboratory values. The POC device uses whole blood and is calibrated for normal hematocrit and platelet counts,

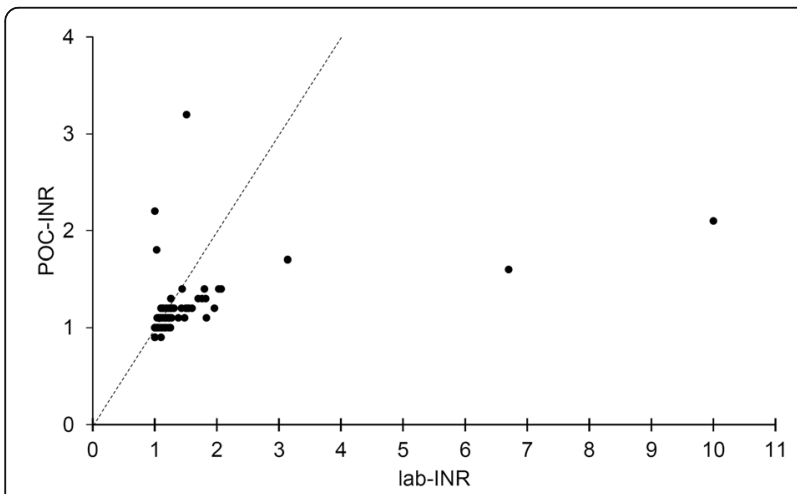

Fig. 2 Scatter plot of point-of-care INR values (POC-INR, Y-axis) against laboratory INR measurements (lab-INR, X-axis) for the 98 patients. The correlation between these values was weak with a Pearson's coefficient equal to 0.44 [95\% Cl 0.27-0.59]. The dash-line represents the ideal linear relationship between the two methods

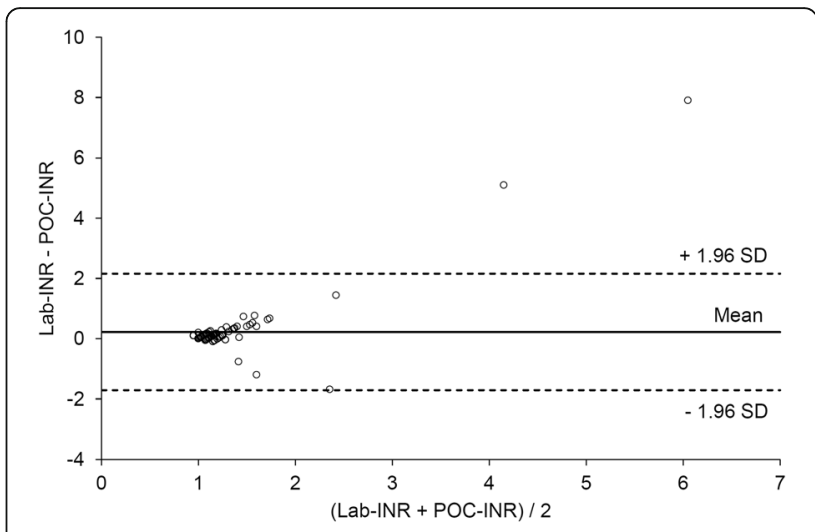

Fig. 3 Bland and Altman plot. The difference between the laboratory INR (lab-INR) and the point-of-care INR (POC-INR) is plotted against the mean of lab-INR and POC-INR for 98 paired measurements in the study. For each data point, the mean value [(lab-INR + POC-INR)/2] is on the $x$ axis and the difference (lab-INR - POC-INR) on the y axis

whereas lab-INRs are measured on plasma. After severe trauma, fluctuations of hematocrit or platelet counts are susceptible to interfere with POC measurements. In the laboratory, the use of platelet-depleted plasma through centrifugation decreases inter-individual differences induced by changes in platelet count. These considerations on preanalytical technique may account for moderate agreement between the two methods. Another explanation may be the influence of fluid resuscitation on blood composition after severe trauma. The use of crystalloids or macromolecules for fluid loading contributes to the modification of blood in resuscitated patients and may affect the precision of the POC method. In our study, a high proportion of patients had fluid therapy $>20 \mathrm{ml} / \mathrm{kg}$, which probably accounted for the disagreement between the two methods. According to French guidelines, patients were also largely treated with vasopressor. The influence of vasopressor use on POC-INR measurements remains unknown but might be limited as compared to the effect of fluid loading. Finally, changes in fibrinogen concentration are also critical to interpret the disagreement between the laboratory method and the POC method. The POC measurement of INR is based upon an electrochemical method using a thrombin substrate and, thus, is not sensitive to fibrinogen concentration. Conversely, the lab-INR determination is based upon a mechanical detection of the clot formation, which is dependent on fibrinogen concentration. As a result, variation in fibrinogen concentration largely affected the concordance between the two methods.

We acknowledge several limits of our study. First, few patients presented with severe acute traumatic coagulopathy and the concordance between the POC device and the laboratory would be of interest in a more diverse trauma population. Second, a low proportion of eligible patients were finally analyzed and only 98 patients out 
of 100 included patients were considered after the exclusion of two wrongly included patients. Reasons for exclusion are detailed in Fig. 1 and our cohort could not be considered as consecutive. However, we experienced technical failure with the POC device and its frequent calibration limits the availability of the device 24/7. Third, the definition of TIC was based upon INR measurements, which might not reflect all aspects of coagulation impairment related to trauma, like platelet dysfunction or fibrinolysis. Although our study disqualifies the use of POC-INR to assess coagulation process after severe trauma, we think that viscoelastic methods are more comprehensive and we encourage the development of such bedside assessment in severe trauma.

\section{Conclusion}

POC INR device was not sufficiently reliable to promote its use in the trauma bay for bedside INR measurement. Poor agreement between this technique and the classic laboratory test may compromise the diffusion of such device for the management of severe trauma patients.

\section{Acknowledgements}

We want to thank Audrey Guyard for statistical support and all nurses involved in the trauma bay for participating in this study.

\section{Funding}

Roche laboratory provided the Coagucheck ${ }^{\oplus}$ XS Pro device and strips for the study. Execution of the study was solely funded by public source (Grenoble University Hospital, France).

\section{Availability of data and materials}

The authors can share their data if requested by any reader of the present study.

\section{Authors' contribution}

$T M, Y B, P M, J L B, P A, J F P$ and PB conceived the study and designed the trial. $T M, Y B, J B, J G$ and $P B$ supervised the conduct of the trial and data collection. $T M, Y B, J B, J G$ and $P B$ undertook recruitment of patients. PB, PA, JFP and JLB provided statistical advice on study design and analyzed the data. TM, JLB, PA, JFP and PB drafted the manuscript, and all authors contributed substantially to its revision. PB takes responsibility for the paper as a whole. All authors read and approved the final manuscript.

\section{Competing interests}

Roche laboratory provided the Coagucheck XS Pro device and strips for the study. Study design, analysis, and writing of the manuscript were performed independently.

\section{Consent for publication}

Not applicable.

\section{Ethics approval and consent to participate}

The Regional Institutional Ethics Committee (CECIC Rhône-Alpes-Auvergne, Clermont-Ferrand, IRB file number 2015-03, approval on January 13, 2015) approved the study design and, given its observational nature, waived the requirement for written informed consent. The study is recorded in clinicaltrials.gov, number: NCT02869737.

\section{Publisher's Note}

Springer Nature remains neutral with regard to jurisdictional claims in published maps and institutional affiliations.

\section{Author details}

Grenoble Alpes Trauma Center, Pôle Anesthésie-Réanimation, CHU Grenoble Alpes, F-38000 Grenoble, France. ${ }^{2}$ University Grenoble Alpes, F-38000 Grenoble, France. ${ }^{3}$ INSERM U1216, F-38000 Grenoble, France. ${ }^{4}$ Pôle Santé Publique, CHU Grenoble Alpes, F-38000 Grenoble, France.

Received: 21 March 2017 Accepted: 13 June 2017

Published online: 21 June 2017

\section{References}

1. Chang R, Cardenas JC, Wade CE, Holcomb JB. Advances in the understanding of trauma-induced coagulopathy. Blood. 2016;128:1043-9.

2. Rossaint R, Bouillon B, Cerny V, Coats TJ, Duranteau J, Fernández-Mondéjar $E$, et al. The European guideline on management of major bleeding and coagulopathy following trauma: fourth Edition. Crit Care. 2016;20:100.

3. Frith D, Goslings JC, Gaarder C, Maegele M, Cohen MJ, Allard S, et al. Definition and drivers of acute traumatic coagulopathy: clinical and experimental investigations. J Thromb Haemost. 2010;8:1919.

4. Peltan ID, Vande Vusse LK, Maier RV, Watkins TR. An international normalized ratio-based definition of acute traumatic coagulopathy is associated with mortality, venous thromboembolism, and multiple organ failure after injury. Crit Care Med. 2015;43:1429.

5. Callcut RA, Johannigman JA, Kadon KS, Hanseman DJ, Robinson BRH. All massive transfusion criteria are not created equal: defining the predictive value of individual transfusion triggers to better determine who benefits from blood. J Trauma. 2011;70:794.

6. Goodman MD, Makley AT, Hanseman DJ, Pritts TA, Robinson BRH. All the bang without the bucks: defining essential point-of-care testing for traumatic coagulopathy. J Trauma Acute Care Surg. 2015;79:117.

7. Gauss T, Hamada S, Jurcisin I, Dahmani S, Boudaoud L, Mantz J, et al. Limits of agreement between measures obtained from standard laboratory and the point-of-care device hemochron signature Elite(R) during acute haemorrhage. Br J Anaesth. 2014;112:514.

8. Mitra B, O'Reilly G, Collecutt M, Cameron PA, Phillips L, Davis A. Prospective comparison of point-of-care international normalised ratio measurement versus plasma international normalised ratio for acute traumatic coagulopathy. Emerg Med Australas. 2012;24:363.

9. David J-S, Levrat A, Inaba K, Macabeo C, Rugeri L, Fontaine O, et al. Utility of a point-of-care device for rapid determination of prothrombin time in trauma patients: a preliminary study. J Trauma Acute Care Surg. 2012;72:703.

10. Taborski U, Braun SL, Völler H. Analytical performance of the new coagulation monitoring system INRatio for the determination of INR compared with the coagulation monitor Coaguchek S and an established laboratory method. J Thromb Thrombolysis. 2004;18:103.

11. Hemkens $L G$, Hilden KM, Hartschen S, Kaiser T, Didjurgeit U, Hansen R, et al. A randomized trial comparing INR monitoring devices in patients with anticoagulation self-management: evaluation of a novel error-grid approach J Thromb Thrombolysis. 2008:26:22.

12. Torreiro EG, Fernández EG, Rodríguez RM, López CV, Núñez JB. Comparative study of accuracy and clinical agreement of the CoaguChek XS portable device versus standard laboratory practice in unexperienced patients. Thromb Haemost. 2009;101:969.

13. Christensen TD, Larsen TB. Precision and accuracy of point-of-care testing coagulometers used for self-testing and self-management of oral anticoagulation therapy. J Thromb Haemost. 2012;10:251.

14. Heneghan CJ, Garcia-Alamino JM, Spencer EA, Ward AM, Perera R, Bankhead $C$, et al. Self-monitoring and self-management of oral anticoagulation. Cochrane Database Syst Rev. 2016;7:CD003839.

15. Heneghan C, Ward A, Perera R, Self-Monitoring Trialist C, Bankhead C, Fuller $\mathrm{A}$, et al. Self-monitoring of oral anticoagulation: systematic review and meta-analysis of individual patient data. Lancet (London, England). 2012;379:322.

16. Toulon P, Ozier Y, Ankri A, Fléron M-H, Leroux G, Samama CM. Point-of-care versus central laboratory coagulation testing during haemorrhagic surgery A multicenter study. Thromb Haemost. 2009;101:394.

17. Cotte J, Lacroix G, D'Aranda E, Kaiser E, Meaudre E. Management of traumatic coagulopathy during long-distance medical evacuation: utility of the Coaguchek $\left(^{(}\right)$XS pro. Annales Françaises D'anesthèsie Et De Rèanimation. 2013;32:122. 
18. Celenza A, Skinner K. Comparison of emergency department point-of-care international normalised ratio (INR) testing with laboratory-based testing. Emerg Med J. 2011;28:136.

19. Beynon C, Erk AG, Potzy A, Mohr S, Popp E. Point of care coagulometry in prehospital emergency care: an observational study. Scand J Trauma Resusc Emerg Med. 2015;23:58.

Submit your next manuscript to BioMed Central and we will help you at every step:

- We accept pre-submission inquiries

- Our selector tool helps you to find the most relevant journal

- We provide round the clock customer support

- Convenient online submission

- Thorough peer review

- Inclusion in PubMed and all major indexing services

- Maximum visibility for your research

Submit your manuscript at www.biomedcentral.com/submit 